\title{
Expression of the Scots pine (Pinus sylvestris) TIP-like and sucrose synthase genes during two growing seasons and correlation with relative wood densities
}

\author{
Krista Kānberga-Siliṇa ${ }^{1 *}$, Āris Jansons² ${ }^{2}$ Dainis Ruṇǵis ${ }^{1}$ \\ ${ }^{1}$ Genetic Resource Centre, Latvian State Forest Research Institute "Silava”, Rigas 111, Salaspils LV-2169, Latvia \\ ${ }^{2}$ Forest Tree Breeding, Latvian State Forest Research Institute "Silava”, Rigas 111, Salaspils LV-2169, Latvia \\ *Corresponding author, E-mail: krista.silina@silava.lv
}

\begin{abstract}
Scots pine is one of the dominant tree species in Latvian forests and has great ecological, social and economic importance globally. Research on connecting molecular data with phenotype is still developing for non-model plant species. To study the linkages between gene expression and desirable wood properties in Scots pine and to determine the dynamics of gene expression for organisms growing in field conditions, we investigated the expression of two genes, previously reported to be involved in wood formation processes. Fifty Scots pine individuals with differing relative wood densities were analysed at one time point during early and late wood formation during the first growing season. During the second growing season, a subset of fifteen trees with large gene expression differences detected during the first season were analysed at four time points during early wood formation and five time points during late wood formation. We found that during both growing seasons, sucrose synthase gene expression tended to be higher for trees with higher wood density, while the tonoplast intrinsic protein-like gene was more highly expressed in trees with lower wood density. Both genes showed differential gene expression dynamics during the second growth season, but at some time points there was correlation with gene expression in the first season.
\end{abstract}

Key words: gene expression dynamics, Pinus sylvestris, Scots pine, SuSy, TIP-like.

Abbreviations: AQP, aquaporin; EST, expressed sequence tag; EW, early wood; HD, high density; LD, low density; LW, late wood; MIP, major intrinsic protein; NIP, NOD26-like intrinsic protein; PIP, plasma membrane intrinsic protein; SAGE, serial analysis of gene expression; SIP, small basic intrinsic protein; SuSy, sucrose synthase; SuSy, sucrose synthase gene; TIP, tonoplast intrinsic protein; TIPl, tonoplast intrinsic protein like gene.

\section{Introduction}

Scots pine (Pinus sylvestris L.) is one of the most widely distributed conifers in the world (Lev-Yadun, Sederoff 2000). Conifer wood formation in temperate regions has an annual pattern of early wood (EW) formation in spring/ summer and late wood (LW) formation in late summer and autumn when cell division activity decreases (Uggla et al. 2001). Thus, early wood and late wood tracheids differ in diameter and cell wall thickness (Lev-Yadun, Sederoff 2000). Early wood consists of thin-walled cells with larger cell lumens, whereas late wood tracheids have narrower lumens and thicker cell walls (Uggla et al. 2001). These characteristics are affected by water and sugar resource allocation during the growth season. Early wood cell formation is considered to be highly dependent on the availability of soil water and sugars are used mainly for shoot and needle growth, not xylogenesis. When apical growth ceases, carbohydrates are also used for LW tracheid cell wall construction (Yang, Loopstra 2005). Early wood has higher lignin content, lower hemicellulose and cellulose content, and lower density (Li et al. 2009).
Desirable wood properties vary depending on potential wood/timber usage. Tree breeding efforts have mostly concentrated on rapid radial growth (Wegner et al. 2010). Wood density is one of the most important wood quality parameters, but negative correlations have been reported in some studies between fast growth and wood density (Plomion et al. 2001). The wood density of $P$. sylvestris increases in the juvenile phase up to age 15 and then stabilizes in the mature phase, but there is a strong correlation between wood density in juvenile and mature wood (Hannrup et al. 1998). In Scots pine, wood density strongly correlates with late wood percentage, which is affected by growth rate and tree age (Peltola et al. 2009). High heritability for wood density was detected in $P$. sylvestris progeny trials in Sweden (Hannrup et al. 1998), as well as for other gymnosperm species (Vargas-Hernandes, Adams 1994). In Pinus radiata, a correlation was found between wood density and modulus of elasticity $(r=0.5$; Kumar et al. 2004).

Despite the economic and ecological importance of conifer species, genomic studies and tools have only recently started to be developed due to large genome sizes, 
and high-quality genomic information generated by large scale sequencing projects is still not available for many tree species, including Scots pine (Neale et al. 2013). A range of studies have been done in various conifer species examining the correlation between wood formation and properties with gene expression, using microarrays and EST sequences of genes involved in a broad spectrum of biochemical pathways (Allona et al. 1998; Lorenz, Dean 2002; Egertsdotter et al. 2004; Kumar et al. 2009; Li et al. 2010). Aquaporins (AQP) are a large group of channel proteins, which facilitate transport of water, some small solutes (urea, boric acid, silicic acid) and some gases (e.g. $\mathrm{CO}_{2}$ ), and even hydrogen peroxide in living organisms (Tyerman et al. 2002; Martinez-Ballesta et al. 2009; Heinen et al. 2009; Yue et al. 2014). AQPs belong to an even larger group of ancient channel proteins, called major intrinsic proteins (MIPs; Chrispeels, Maurel 1994; Schaffner et al. 1998). In plants, MIPs are highly diverse, due to the physiological importance of MIPs or AQPs, and the multiple mechanisms involved in water uptake and evaporation in plants (Zardoya, Villalba 2001; Abascal et al. 2014). Plant AQPs are divided into four subfamilies: TIPs (tonoplast intrinsic proteins), PIPs (plasma membrane intrinsic proteins), SIPs (small basic intrinsic proteins) and NIPs (NOD26-like intrinsic proteins) (Zardoya 2005; Di Giorgio et al. 2014). Some of the most abundant AQPs are PIPs and TIPs, which are involved in rapid water transport and maintenance of water balance in cells, as the gene products (proteins) of this subfamily, mediate stomatal closure (Maurel et al. 2008; Laur, Hacke 2014; Yue et al. 2014). Some of the most broadly expressed TIP paralogs are TIP2:1, TIP1:2 and TIP1:1 (Abascal et al. 2014). In Picea glauca, TIP2:1 is detected in roots, stems, needles, reproductive parts, while TIP2:2 is detected only in stems (Laur, Hacke 2014). TIP overexpression in transgenic plants has been associated with increased plant growth rate and biomass production (Rodrigues et al. 2013).

Expression of AQPs is associated with plant growth, especially cell division, elongation and differentiation (Yue et al. 2014; Novikova et al. 2014). Overexpression of some TIPs and PIPs can also enhance tolerance to low temperatures (Yue et al. 2014). Serial analysis of gene expression (SAGE) of a single 10 year old loblolly pine tree revealed that various aquaporins are among the most abundant transcripts in lignifying loblolly pine xylem (Lorenz, Dean 2002), this was further confirmed by Yang et al. (2004). It has been reported that aquaporinlike gene expression positively affects wood maturation, with a positive correlation between aquaporin-like gene expression and wood properties such as LW density, EW cell diameter, EW wall thickness, EW lumen diameter, LW cell diameter, LW wall thickness, LW percentage, and tracheid length (Kumar et al. 2009). In P. radiata, a cDNA microarray study comparing transcript abundance during EW and LW formation with wood property data obtained using Silviscan found that aquaporin and MIP2 transcripts were more highly accumulated in EW, while a different aquaporin like gene was more abundant in LW, demonstrating the diverse regulation patterns of channel protein coding transcripts (Li et al. 2010).

Sucrose synthase (SuSy) is one of the two main enzymes catalysing sucrose hydrolysis and formation of UDPglucose and fructose (Coleman et al. 2009). SuSy has been linked with the synthesis of both storage and structural carbohydrates, also with channelling UDP-glucose into the cellulose synthase complex (Delmer, Amor 1995). In Arabidopsis and rice there are six SuSy family genes with various expression patterns and localizations (Bieniawska et al. 2007; Hirose et al. 2008). There are also multiple SuSy genes in Pinus taeda, but only one is highly expressed (Nairn et al. 2008). In poplar, much higher SuSy transcript levels were detected in leaves than in xylem (Coleman et al. 2009). Analysing microarray data from P. taeda it was found, that SuSy transcripts were more abundant in LW compared to EW (Egertsdotter et al. 2004; Yang, Loopstra 2005), and a similar result was found in $P$. radiata (Li et al. 2010). Two different SuSy gene transcripts analysed in Egertsdotter et al. (2004) showed fluctuations in transcript abundance during the growth season, with lower values in spring and increased expression in October. Increased activity of SuSy was detected in $P$. sylvestris tracheids undergoing secondary cell wall formation (Uggla et al. 2001).

The aim of this study was to determine the expression of two genes ( $T I P l$ and SuSy), previously reported to be involved in wood formation processes, in Scots pine trees with differing relative wood densities. TIPl and SuSy gene expression was determined at two time points (during EW and LW formation) for fifty trees during the first growing season. Subsequently, a more detailed analysis of gene expression was undertaken for fifteen trees with significant gene expression differences detected during the first growing season. Gene expression levels were determined at four time points during EW and five time points during LW formation during the second growing season. Correlation of gene expression with relative wood density as a representative wood quality trait as well as changes in gene expression during the second growing season and correlation with expression during the first growing season were determined.

\section{Materials and methods}

\section{Candidate gene selection and primer design}

Genes analysed in this study were selected based on previously published studies and the availability of gene sequences from pine species. Gene sequences for primer design were obtained from the NCBI database (http://www. ncbi.nlm.nih.gov/), Aqual Genbank accession number EU301695.1, SuSy EF619967.1. Taking in consideration the available aquaporin and aquaporin-like sequences 
and current nomenclature, and as the utilised Aqual gene had more than $70 \%$ identity with annotated TIPs in other plant species, this gene was designated TIP-like $(T I P l)$. Primers for candidate genes were selected using the program Primer3 (http://frodo.wi.mit.edu/), FastPCR (http://primerdigital.com/fastpcr.html) and checked by NetPrimer (http://www.premierbiosoft.com/netprimer/). For each gene, seven primer pairs were tested and the pair with the highest PCR effectivity was selected for further real time PCR analysis. TIPl gene primers used for real time PCR were forward 5'-CCTTGGCGGCCAGATCACCA-3', reverse 5'GCCGCCGGTGACGAACTTGA3'; SuSyforward 5'-CAAGACTCGACCGGGTTAAA-3', reverse 5'-TTCGGCCACTTCTTCTCTGT-3'. GAPDH primers were utilized as endogenous controls as described previously (Škipars et al. 2011). A subset of the samples were also analyzed with two other endogenous control genes, $\beta$-actin and $\alpha$-tubulin, but as expression trends were similar, only GAPDH was used for further analyses.

\section{Plant material}

The plant material for gene expression analysis was collected from a pine plantation consisting of plus tree half-sib families, established in 1982 in central Latvia (Vecumnieki, $56^{\circ} 41^{\prime} \mathrm{N}, 24^{\circ} 26^{\prime} \mathrm{E}$ ). Distance between trees was $2 \times 1 \mathrm{~m}$ and there was no thinning done in this site. Sampled trees were open pollinated progenies from four populations growing in different regions of Latvia. Individuals with high wood density represented four families, and individuals with low wood density were from six half-sib families.

\section{Relative wood density determination}

Relative wood density was measured using the PILODYN 6J-Forest instrument (Hansen 2000). For gene expression analysis, fifty 30 year old trees were selected, from which 25 had higher relative wood density and 25 had lower relative wood density.

\section{Sample collection for RNA extraction}

Samples were collected at one time point during first season, in spring (April-May) during early wood (EW) formation and during late wood (LW) formation in late summer/ autumn (August-September). Second season samples were gathered from 15 trees that showed large differences in gene expression during the first season. During the second season, samples were gathered at four time points during EW formation and five times during LW formation. Cambium/xylem tissues were obtained at $1 \mathrm{~m}$ height above the tree base by removing the bark and scraping off the underlying soft tissue with a scalpel. Tissues were placed into microtubes and immediately stored in liquid nitrogen.

\section{RNA extraction}

An adapted CTAB buffer based method was used for RNA extraction, (Chang et al. 1993; Rubio-Piña, Zapata-Pérez
2011). RNA quantity was assessed fluorometrically using a Qubit fluorometer and Quant-iTreagents (Invitrogen) following the manufacturer's instructions. RNA extracts were treated with DNase I (Thermo Fisher) and purified using phenol/chloroform extraction. RNA purity was verified by standard PCR reaction and gel electrophoresis in a $1.2 \%$ agarose gel, stained with ethidium bromide. RNA integrity was checked using Bioanalyzer 2100 (Agilent Technologies), following the manufacturer's instructions. For all samples, RNA Integrity Number was higher than seven.

\section{CDNA synthesis}

Samples of total RNA $(1 \mu \mathrm{g})$ were reverse transcribed in a $50 \mu \mathrm{L}$ reaction using Taqman reverse transcription reagents (Invitrogen) and Oligo(dT)18 primer (Thermo Fisher) according to the manufacturer's instructions. cDNA for standard curves was obtained from $2 \mu \mathrm{g}$ total RNA per reaction. cDNA quality was checked using a PCR reaction with primers that span an exon-exon junction and visualized by gel electrophoresis.

\section{Real time $P C R$}

Gene expression analysis was performed using relative standard curve real time PCR method and carried out on an Applied Biosystems StepOnePlus 96-well real-time PCR system using a standard three step real time PCR protocol. For real-time PCR, the Maxima SYBR Green PCR kit (Thermo Fisher) in a total volume of $20 \mu \mathrm{L}$ containing 2 $\mu \mathrm{L}$ of $\mathrm{cDNA}$ and $0.15 \mu \mathrm{M}$ of each primer was used. Each sample was run in three technical replicates for each candidate gene and the endogenous control gene GAPDH was run on the same plate. After amplification, dissociation curves were checked for detection of primer dimers and other non-specific PCR products. Standard curves for gene expression quantification were calculated from 1:5 serial dilutions of cDNA used in this study.

\section{Data analysis}

Data were analysed using StepOne software v2.2, ANOVA and Pearson correlation. Transcript levels of candidate genes were calculated as a percentage of GAPDH gene expression in the same sample. Samples were grouped according to wood density [high density (HD) and low density (LD)] as well as time point [early wood (EW) and late wood (LW)] for further analysis.

\section{Results}

\section{TIPI and SuSy gene expression during the first growing} season

TIPl gene expression during EW formation was more than ten times higher than SuSy gene expression. The TIPl gene was significantly $(P<0.05)$ overexpressed in trees with lower wood density during EW formation, whereas SuSy 
had slightly increased expression in trees with higher wood density, but the difference was not statistically significant. During LW formation, no significant differences in TIPl and SuSy gene expression between trees with high and low wood density were observed. During the first season both gene transcripts were more highly expressed in EW (Table $1)$.

\section{TIPI and SuSy gene expression during the second growing season}

During the second growing season, tissue samples were obtained from fifteen trees that were sampled four times during EW and five times during LW formation. During EW formation, the TIPl and SuSy genes had differing expression patterns. SuSy gene expression during EW formation increased over the course of the growth season, with lower expression found in trees with lower wood density (Fig. 1). SuSy expression during EW formation

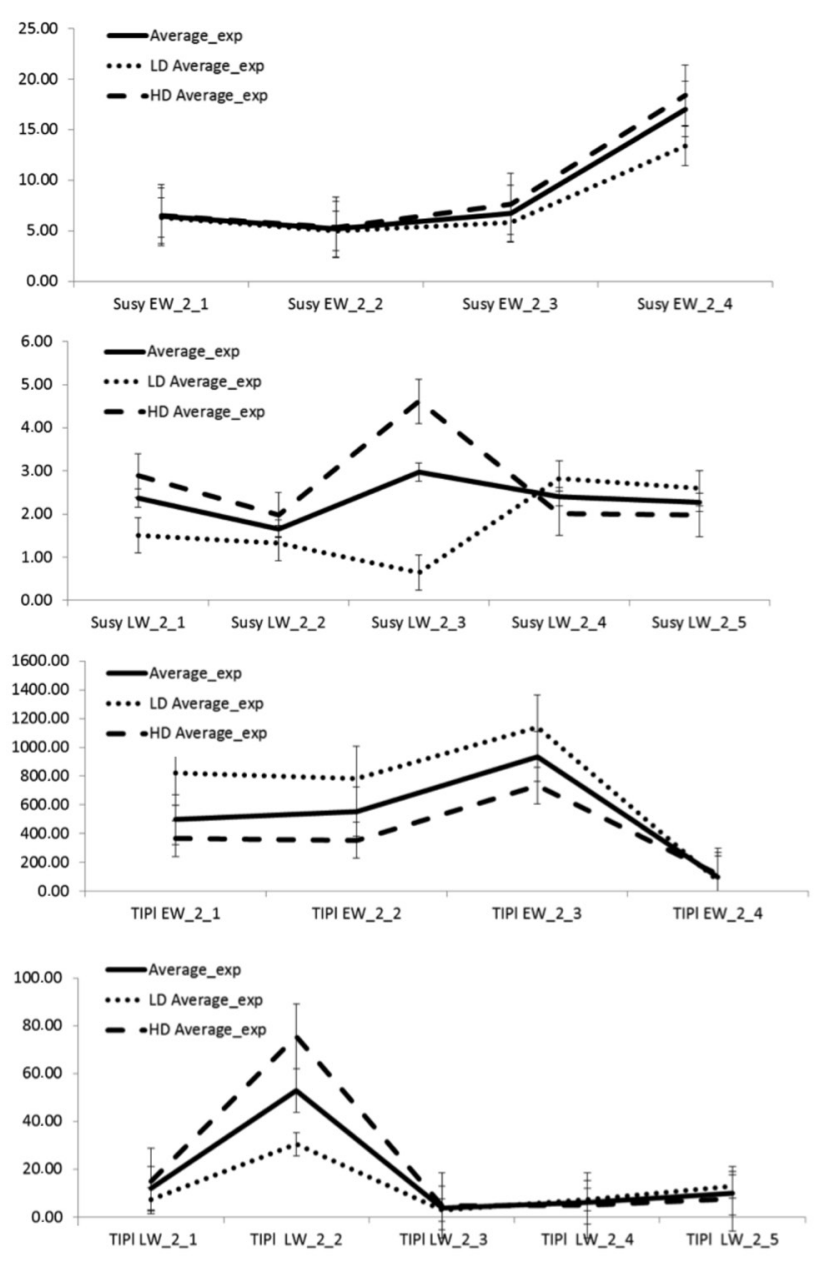

Fig. 1. TIPl and SuSy gene expression profiles during the second growing season. Panels A and B: SuSy gene expression as \% of GAPDH expression during early (EW) and late (LW) wood formation with standard errors shown. Panels C and D: TIPl gene expression as \% of GAPDH expression during EW and LW formation.
Table 1. TIPl and SuSy gene expression for fifty trees with high (HD) and low (LD) wood density during early (EW) and late (LW) wood formation during the first growing season. Mean gene expression given as percentage of GAPDH gene expression

\begin{tabular}{lccc}
$\begin{array}{l}\text { Gene/wood } \\
\text { formation } \\
\text { stage }\end{array}$ & $\begin{array}{c}\text { Mean } \\
\text { expression }\end{array}$ & $\begin{array}{c}\text { HD mean } \\
\text { expression }\end{array}$ & $\begin{array}{c}\text { LD mean } \\
\text { expression }\end{array}$ \\
\hline SuSy EW & 88.50 & 100.00 & 77.95 \\
\hline TIPl EW & 1043.73 & 626.43 & 1462.88 \\
SuSy LW & 3.60 & 4.53 & 2.53 \\
\hline TIPl LW & 70.15 & 71.66 & 68.88
\end{tabular}

was not significantly different between trees with HD and LD. During LW formation, SuSy expression was lower for trees with $L D$ and showed a differing expression profile between HD and LD trees at the third time point. During LW formation, SuSy expression at the third time point was significantly lower in trees with lower wood density.

During EW development, expression of the TIPl gene declined at the final time point. TIPl gene expression was higher for trees with lower wood density, with highest expression at the third time point. TIPl gene expression was higher for trees with LD at three of four sampling times. During LW formation, TIPl gene expression peaked at the second time point, and in contrast to expression during EW time points, the highest TIPl expression was found in trees with higher wood density (Fig. 1).

\section{Comparison of TIPI and SuSy gene expression between the two growing seasons}

Of the time points sampled during the second growth season, the most similar to the sampling times of the first growing season were the $4^{\text {th }}$ time point for $\mathrm{EW}$ formation and the $3^{\text {rd }}$ time point for LW formation. Significant correlations were detected between SuSy expression during EW formation in first season and SuSy expression at the third and fourth time points in the second growing season (SuSy_EW_2_3 and SuSy_EW_2_4) points $(r=0.810$ and $r=0.909 ; P<0.01$ ) (Table 2). During LW formation, a significant correlation was found for SuSy expression in the first season and the third sampling point in the second season $(P<0.01)$.

For the TIPl gene, significant correlations were also found between gene expression in the first season during EW formation and the first and second time points of the second growing season $(P<0.01)$. A significant correlation was also found between TIPl gene expression in the first season during $\mathrm{LW}$ formation with the first time point of the second season $(r=0.738 ; P<0.01)$.

\section{Discussion}

The genes investigated were selected based on previous reports indicating their possible significant role in wood formation. AQPs have been reported to control movement 
Table 2. Correlations between $\mathrm{TIPl}$ and SuSy gene expression during the first (s1) and second (s2) growing seasons during early (EW) and late (LW) wood formation

\begin{tabular}{|c|c|c|c|c|c|}
\hline & SuSy_EW_s1 & SuSy_EW_s2_tp1 & SuSy_EW_s2_tp2 & SuSy_EW_s2_tp3 & SuSy_EW_s2_tp4 \\
\hline SuSy_EW_s1 & 1 & & & & \\
\hline SuSy_EW_s2_tp1 & 0.294 & 1 & & & \\
\hline SuSy_EW_s2_tp2 & -0.238 & 0.859 & 1 & & \\
\hline SuSy_EW_s2_tp3 & 0.810 & 0.342 & -0.042 & 1 & \\
\hline \multirow[t]{2}{*}{ SuSy_EW_s2_tp4 } & 0.909 & 0.472 & -0.013 & 0.756 & 1 \\
\hline & TIP1_EW_s1 & TIP1_EW_s2_tp1 & TIP1_EW_s2_tp2 & TIP1_EW_s2_tp3 & TIP1_EW_s2_tp4 \\
\hline TIP1_EW_s1 & 1 & & & & \\
\hline TIP1_EW_s2_tp1 & 0.754 & 1 & & & \\
\hline TIP1_EW_s2_tp2 & 0.783 & 0.907 & 1 & & \\
\hline TIP1_EW_s2_tp3 & 0.678 & 0.751 & 0.891 & 1 & \\
\hline \multirow[t]{2}{*}{ TIP1_EW_s2_tp4 } & -0.071 & -0.138 & -0.135 & -0.171 & 1 \\
\hline & TIP1_LW_s1 & TIP1_LW_s2_tp1 & TIP1_LW_s2_tp2 & TIP1_LW_s2_tp3 & TIP1_LW_s2_tp4 \\
\hline TIP1_LW_s1 & 1 & & & & \\
\hline TIP1_LW_s2_tp1 & 0.738 & 1 & & & \\
\hline TIP1_LW_s2_tp2 & -0.153 & -0.212 & 1 & & \\
\hline TIP1_LW_s2_tp3 & -0.135 & -0.317 & -0.201 & 1 & \\
\hline TIP1_LW_s2_tp4 & 0.607 & 0.488 & 0.112 & -0.209 & 1 \\
\hline \multirow[t]{2}{*}{ TIP1_LW_s2_tp5 } & -0.139 & 0.126 & 0.072 & -0.146 & -0.145 \\
\hline & SuSy_LW_s1 & SuSy_LW_s2_tp1 & SuSy_LW_s2_tp2 & SuSy_LW_s2_tp3 & SuSy_LW_s2_tp4 \\
\hline SuSy_LW_s1 & 1 & & & & \\
\hline SuSy_LW_s2_tp1 & -0.114 & 1 & & & \\
\hline SuSy_LW_s2_tp2 & 0.095 & -0.066 & 1 & & \\
\hline SuSy_LW_s2_tp3 & 0.768 & 0.136 & -0.119 & 1 & \\
\hline SuSy_LW_s2_tp4 & 0.607 & -0.508 & 0.333 & -0.218 & 1 \\
\hline SuSy_LW_s2_tp5 & 0.012 & -0.467 & 0.282 & -0.040 & 0.079 \\
\hline
\end{tabular}

of water and other small solutes, and their involvement in plant growth and development has also been reported (Zardoya, Villalba 2001; Zardoya 2005; Abascal et al. 2014; Di Giorgio et al. 2014; Novikova et al. 2014) and they have been reported as one of most abundant transcript families in P. taeda xylem (Lorenz, Dean 2002). AQPs are represented by large gene families with various functions in a wide range of species (Yue et al. 2014), but most TIPs are classified as probable or confirmed aquaporins (Beaulieu et al. 2011). In some cases, the gene expression patterns described in his study differed from previously published reports. This may be a result of the analyzed genes being members of gene families, with various members having differing functions, localization or expression profiles, as well as species differences. In addition, the results presented in this report are average expression levels over a number of individuals, while the previous reports were mostly based on analysis of a single individual. Expression levels of three lignin biosynthesis genes were previously investigated in the same plant material (Kanberga-Silina et al. 2015), and large differences in expression levels were detected between individuals. This variation of gene expression between individuals also needs to be considered when comparing gene expression levels.

An aquaporin like gene was reported to be more abundant during LW formation while a different aquaporin gene and the MIP-2 gene were reported to be more abundant in EW (Li et. al. 2010). As our primers were based on the $P$. radiata aquaporin-like gene sequence, we expected that the expression pattern in P. sylvestris may be similar to that in $P$. radiata, and it would be more abundant during LW formation. However, our results identified the opposite expression pattern, as TIPl was more than ten times more highly expressed during EW formation (both for trees with $\mathrm{HD}$ and $\mathrm{LD}$ ) than during LW formation, therefore suggesting a functional role as an aquaporin, facilitating transfer of solutes in the early part of the growing season. During the second season, TIPl gene was also more highly expressed during EW formation, corresponding to the result from the first season. One explanation for these differing expression profiles might be that these genes are paralogous between $P$. radiata and $P$. sylvestris and do not share the same function in the two species. $P$. radiata is not also closely phylogenetically related to P. sylvestris (Gernandt et al. 2005). It is possible that a different member of this gene family is performing the function of the $P$. radiata TIPl gene in $P$. sylvestris. A more thorough phylogenetic analysis of this gene family is necessary to identify all of the functional members in the P. sylvestris genome. The results obtained by Li et. al. (2010) were based 
on microarray data from $P$. radiata trees of various ages and although the expression of a subset of their identified candidate genes was confirmed using multiple ligationdependent probe amplification (MLPA), the TIPl gene was not, and therefore direct comparison can be made between the two studies.

The TIPl gene was significantly overexpressed in trees with lower wood density during EW formation in the first season. As EW wood has wider cell lumens and thinner cell walls (Uggla et al. 2001), then faster growth facilitated by aquaporins can lead to lower wood density. However, there is evidence that expression of some aquaporin-like genes is positively correlated with wood properties such as LW density and EW cell wall thickness (Kumar et al. 2009). TIPl expression during EW formation in the second season was higher for trees with low wood density. However, the statistically significant difference in TIPl gene expression between trees with high and low wood density was not confirmed by statistically significantly differing results from the second season, possibly due to the smaller number of analyzed individuals.

A sucrose synthase sequence was reported by Li et. al. (2009) as one of thirty most abundant EST transcripts in $P$. radiata and Li et al. (2010) reported SuSy to be preferentially transcribed in juvenile wood with high stiffness and low microfibril angle. Yang and Loopstra (2005) reported that SuSy transcripts were more abundant in LW than EW, however expression of the SuSy was not confirmed using real time PCR as was done for some other genes identified in this report. Our results indicated that SuSy was more highly expressed during EW formation in both seasons. Fluctuations of SuSy transcript levels during the second growing season were slight and not significantly different between trees with HD and LD, except at the third time point during LW formation where in trees with HD, SuSy expression was significantly higher. These changes may be related to specific activity of transcriptional factors influencing SuSy expression, or, as mentioned previously, multiple members of the SuSy gene family may have differentiated to perform differing roles. Nairn et al. (2008) reported that SuSy was more highly expressed in xylem than in phloem for three of four analysed P. taeda trees and that expression profiles of this gene varied slightly between the analysed individual trees at four sampling points (Apr, Jun, Jul, Aug). From our data, SuSy expression did not vary significantly between trees with higher and lower wood density in the first growing season, and differences in mean expression between EW and LW were also not statistically significant. In hybrid poplar, SuSy is considered to provide the largest effect on biomass accumulation and height growth due to increased cellulose synthesis linked with SuSy overexpression (Coleman et al. 2009). Our findings about SuSy gene expression patterns also tend to agree with findings about lack of seasonality for carbohydrate availability and suggestions that the length of the developmental time period of late wood cell walls results in thicker late wood cell walls, but not the pace of cell wall material deposition (Uggla et al. 2001).

The results obtained in this study contribute to our understanding of the expression patterns of these two genes during early and late wood formation during two growing seasons in trees with differing wood properties growing in an uncontrolled field environment. Expression levels of both analysed genes fluctuate over the course of the growing season, and further phylogenetic analysis of both gene families is required to determine the full functional complement of these gene families in P. sylvestris.

\section{Acknowledgements}

The study was partly performed within the framework of the project co-funded by the EU, No. 2009/0200/1DP/1.1.1.2.0/09/ APIA/VIAA/146. The study was also partly funded by the project "Forest tree breeding for establishment of high genetic quality stands".

\section{References}

Abascal F., Irisarri I., Zardoya R. 2014. Diversity and evolution of membrane intrinsic proteins. Biochim. Biophys. Acta Gen. Subj. 1840: 1468-1481.

Allona I., Quinn M., Shoop E., Swope K., Cyr S.S., Carlis J., Whetten R.W. 1998. Analysis of xylem formation in pine by cDNA sequencing. Proc. Natl. Acad. Sci. USA 95: 9693-9698.

Beaulieu J., Doerksen T., Boyle B., Clément S., Deslauriers M., Beauseigle S., Blais S., Poulin P.L., Lenz P., Caron S., Rigault P. 2011. Association genetics of wood physical traits in the conifer white spruce and relationships with gene expression. Genetics 188:197-214.

Bieniawska Z., Barratt D.H.P., Garlick A.P., Thole V., Kruger N.J., Martin C., Zrenner R., Smith A.M. 2007. Analysis of the sucrose synthase gene family in Arabidopsis. Plant J. 49: 810828.

Chang S., Puryear J., Cairney J. 1993. A simple and efficient method for isolating RNA from pine trees. Plant Mol. Biol. Rep. 11: 113-116.

Chrispeels M.J., Maurel C. 1994. Aquaporins: the molecular basis of facilitated water movement through living plant cells? Plant Physiol. 105: 9.

Coleman H.D., Yan J., Mansfield S.D. 2009. Sucrose synthase affects carbon partitioning to increase cellulose production and altered cell wall ultrastructure. Proc. Natl. Acad. Sci. USA 106: 13118-13123.

Delmer D.P., Amor Y. 1995. Cellulose biosynthesis. Plant Cell 7: 987-1000.

Di Giorgio J.P., Soto G., Alleva K., Jozefkowicz C., Amodeo G., Muschietti J. P., Ayub N.D. 2014. Prediction of aquaporin function by integrating evolutionary and functional analyses. J. Membr. Biol. 247: 107-125.

Egertsdotter U., van Zyl L.M., Mackay J., Peter G., Kirst M., Clark C., Whetten R., Sederoff R. 2004. Gene expression during formation of earlywood and latewood in loblolly pine: expression profiles of 350 genes. Plant Biol. 6: 654-663.

Gernandt D.S., López G.G., García S.O., Liston A. 2005. Phylogeny and classification of Pinus. Taxon 54: 29-42. 
Hannrup B., Wilhelmsson L., Danell O. 1998. Time trends for genetic parameters of wood density and growth traits in Pinus sylvestris L. Silvae Genet. 4: 214-219.

Hansen C.P. 2000. Application of the Pilodyn in Forest Tree Improvement. DFSC Series of Technical Notes. TN55. Danida Forest Seed Centre, Humlebaek, Denmark.

Heinen R.B., Ye Q., Chaumont F. 2009. Role of aquaporins in leaf physiology. J. Exp. Bot. 60: 2971-2985.

Hirose T., Scofield G.N., Terao T. 2008. An expression analysis profile for the entire sucrose synthase gene family in rice. Plant Sci. 174: 534-543.

Kanberga-Silina K., Jansons A., Rungis D. 2015. Expression of three phenylpropanoid pathway genes in Scots pine (Pinus sylvestris L.) in open-pollinated families with differing relative wood densities during early and late wood formation. Silvae Gen. 64: 148-159.

Kumar M., Saranpää P., Barnett J.R., Wilkinson M.J. 2009. Juvenilemature wood transition in pine: correlation between wood properties and candidate gene expression profiles. Euphytica 166: 341-355.

Kumar S. 2004. Genetic parameter estimates for wood stiffness, strength, internal checking, and resin bleeding for radiata pine. Can. J. Forest Res. 34: 2601-2610.

Laur J., Hacke U.G. 2014. Exploring Picea glauca aquaporins in the context of needle water uptake and xylem refilling. New Phytol. 203: 388-400.

Lev-Yadun S., Sederoff R. 2000. Pines as model gymnosperms to study evolution,wood formation and perennial growth. J. Plant Growth Reg. 19: 290-305.

Li X., Wu H., Dillon S., Southerton S.G. 2009. Generation and analysis of expressed sequence tags from six developing xylem libraries in Pinus radiata D. Don. BMC Genomics 10: 41.

Li X., Wu H.X., Southerton S.G. 2010. Seasonal reorganization of the xylem transcriptome at different tree ages reveals novel insights into wood formation in Pinus radiata. New Phytol. 187: 764-776.

Lorenz W.W., Dean J.F. 2002. SAGE profiling and demonstration of differential gene expression along the axial developmental gradient of lignifying xylem in loblolly pine (Pinus taeda). Tree Physiol. 22: 301-310.

Martinez-Ballesta M.C., López-Pérez L., Muries B., MuñozAzcarate O., Carvajal M.2009. Climate change and plant water balance: the role of aquaporins - a review. In: Lichtfouse E. (ed) Climate Change, Intercropping, Pest Control and Beneficial Microorganisms. Springer, Netherlands, pp. 71-89.

Maurel C., Verdoucq L., Luu D.T., Santoni V. 2008. Plant aquaporins: membrane channels with multiple integrated functions. Annu. Rev. Plant Biol. 59: 595-624.

Nairn C.J., Lennon D.M., Wood-Jones A., Nairn, A.V., Dean J.F. 2008. Carbohydrate-related genes and cell wall biosynthesis in vascular tissues of loblolly pine (Pinus taeda). Tree Physiol. 28: 1099-1110.
Neale D.B., Langley C.H., Salzberg S.L., Wegrzyn, J.L. 2013. Open access to tree genomes: the path to a better forest. Genome Biol. 14: 120.

Novikova G.V., Tournaire-Roux C., Sinkevich I.A., Lityagina S.V., Maurel C., Obroucheva N. 2014. Vacuolar biogenesis and aquaporin expression at early germination of broad bean seeds. Plant Physiol. Biochem. 82: 123-132.

Peltola H., Gort J., Pulkkinen P., Zubizarreta Gerendiain A., Karppinen J., Ikonen V.P. 2009. Differences in growth and wood density traits in Scots pine (Pinus sylvestris L.) genetic entries grown at different spacing and sites. Silva Fenn. 43:339354.

Plomion C., Leprovost G., Stokes A. 2001. Wood formation in trees. Plant Physiol. 127: 1513-1523.

Rodrigues M.I., Bravo J.P., Sassaki F.T., Severino F.E., Maia I. G. 2013. The tonoplast intrinsic aquaporin (TIP) subfamily of Eucalyptus grandis: Characterization of EgTIP2, a rootspecific and osmotic stress-responsive gene. Plant Sci. 213: 106-113.

Rubio-Piña J.A., Zapata-Pérez O. 2011. Isolation of total RNA from tissues rich in polyphenols and polysaccharides of mangrove plants. Electr. J. Biotechnol. 14: 11-11.

Schaffner A.R. 1998. Aquaporin function, structure, and expression: are there more surprises to surface in water relations? Planta 204: 131-139.

Šķipars V., Krivmane B., Ruņgis D. 2011. Thaumatin-like protein gene copy number variation in Scots pine (Pinus sylvestris L.). Environ. Exp. Biol. 9: 75-81.

Tyerman S.D., Niemietz C.M., Bramley H. 2002. Plant aquaporins: multifunctional water and solute channels with expanding roles. Plant Cell Environ. 25: 173-194.

Uggla C., Magel E., Moritz T., Sundberg B., 2001. Function and dynamics of auxin and carhydrates during early wood/late wood transition in Scots pine. Plant Physiol. 125: 2029-2039.

Vargas-Hernandez J., Adams W.T. 1994. Genetic relationships between wood density components and cambial growth rhythm in young coastal Douglas-fir. Can. J. Forest Res. 24: $1871-1876$.

Zardoya R. 2005. Phylogeny and evolution of the major intrinsic protein family. Biol. Cell 97: 397-414.

Zardoya R., Villalba S. 2001. A phylogenetic framework for the aquaporin family in eukaryotes. J. Mol. Evol. 52: 391-404.

Wegner T., Skog K.E., Ince P.J., Michler C.J. 2010. Uses and desirable properties of wood in the 21 st century. J. Forestry 4: 165-173.

Yang S.H., Loopstra C.A., 2005. Seasonal variation in gene expression for loblolly pines (Pinus taeda) from different geographical regions. Tree Physiol. 25: 1063-1073.

Yue C., Cao H., Wang L., Zhou Y., Hao X., Zeng J., Wang X., Yang Y. 2014. Molecular cloning and expression analysis of tea plant aquaporin (AQP) gene family. Plant Physiol. Biochem. 83: $65-76$. 